\title{
A PARTICIPAÇÃO POPULAR NO PROCESSO DE LICENCIAMENTO AMBIENTAL DA EXPLORAÇÃO PETROLÍFERA NA COSTA DO AMAPÁ: UM ESTUUDO DE CASO SOBRE A CONTRIBUIÇÃO DA AUDIÊNCIA PÚBLICA DO BLOCO FZA-M-59
}

\begin{abstract}
POPULAR PARTICIPATION IN THE ENVIRONMENTAL LICENSING PROCESS FOR PETROLEUM EXPLORATION IN THE AMAPÁ COAST: A CASE STUDY ON THE CONTRIBUTION OF THE PUBLIC HEARING IN BLOCK FZA-M-59
\end{abstract}

Luis Ribeiro de Sousa ${ }^{1}$

https://orcid.org/0000-0001-7215-1412 http://lattes.cnpq.br/3434686456363803

\section{Marcelo José de Oliveira ${ }^{2}$ \\ https://orcid.org/0000-0002-2460-7259 \\ http://lattes.cnpq.br/0612708881662162}

Recebido em: 26 de novembro de 2019

Aprovado em: 29 de agosto de 2020

RESUMO: O presente artigo teve como objetivo avaliar as contribuições da participação popular via audiência pública no processo de licenciamento ambiental da exploração petrolífera de um bloco licitado na Bacia da Foz do Amazonas. Foi realizada uma revisão bibliográfica sobre a temática, seguida de uma análise quantitativa e qualitativa da ata e dos cadernos de presença da audiência pública ocorrida na cidade de Macapá - AP, em novembro de 2017. Por fim, foi analisado o parecer técnico emitido pelo órgão licenciador com a conclusão temporária do processo, o que possibilitou conhecer a efetividade das contribuições. Do ponto de vista quantitativo a participação do público foi baixa, apenas $9 \%$ dos presentes se manifestaram uma ou mais vezes, tendo a categoria cidadão com a maior participação:78\%, sendo formada principalmente por pessoas ligadas à instituições de ensino. Cerca de $74 \%$ das manifestações estavam relacionadas com o EIA-RIMA, o que demonstra que os participantes tomaram conhecimento sobre o empreendimento. As principais preocupações foram em relação aos impactos na pesca e geração de empregos na região, além da modelagem da dispersão de óleo e os riscos aos corais da Amazônia. Verificou-se que algumas dessas preocupações foram destacadas no parecer do órgão licenciador, o que de certa forma parece ter influenciando o IBAMA em sua decisão, o qual optou por solicitar mais informações e

${ }^{1}$ Graduado em Engenharia Química pela UEAP. Especialista em Meio Ambiente, Petróleo e Gás pela UNIFAP. E-mail: luissalut@hotmail.com.

2 Professor adjunto da Universidade Federal do Amapá. Graduação em Geologia pela Universidade Federal do Pará (1994). Especialista em Hidrogeologia Aplicada (1996), mestrado em Geologia e Geoquímica pela Universidade Federal do Pará (1996) e Doutor em Desenvolvimento Sustentável do Trópico Úmido pelo Núcleo de Altos Estudos Amazônicos NAEA - UFPA (2010).E-mail: geomarcelooliveira@gmail.com. 
esclarecimentos para subsidiar sua decisão sobre a licença ambiental para a exploração no bloco FZA-M-59. Assim, conclui-se pela efetiva contribuição da audiência ao processo de licenciamento em análise.

Palavras Chave: Exploração Petrolífera, Licenciamento Ambiental, Audiência Pública, Bacia da Foz do Amazonas.

ABSTRACT: This article aimed to evaluate the contributions of popular participation via public hearing in the process of environmental licensing of oil exploration of a acquired block in the Foz do Amazonas Basin. A bibliographic review of the topic was performed, followed by a quantitative and qualitative analysis of the minutes and attendance records of the public hearing held in the city of Macapá AP in November 2017. Finally, the technical opinion issued by the licensing body with temporary conclusion of the process, which made it possible to know the effectiveness of the contributions. From a quantitative point of view, public participation was low, only $9 \%$ of those present expressed their opinion one or more times, with the citizen category having the largest participation: 78\% and consisting mainly of people linked to educational institutions. About $74 \%$ of the demonstrations were related to EIA-RIMA, which demonstrates that participants learned about the venture. The main concerns were regarding impacts on fishing and job creation in the region, in addition to oil dispersion modeling and the risks to Amazonian corals. It was found that some of these concerns were highlighted in the technical advice of the licensing institution, which seems to have influenced IBAMA in its decision, which opted to request more information and clarification to subsidize its decision on the environmental license for exploration in Brazil. FZA-M-59 block. Thus, it is concluded by the effective contribution of the public hearing for the licensing process under review.

Keywords: Petroleum Exploration, Environmental Licensing, Public Hearing, Foz do Amazonas Basin.

\section{INTRODUÇÃO}

Em 2013 foi realizada pela Agência Nacional de Petróleo, Gás Natural e Biocombustíveis (ANP) a $11^{\circ}$ rodada de licitações para aquisição de blocos exploratórios em 11 bacias sedimentares, entre elas a da Foz do Amazonas (BRASIL, 2013). Com a conclusão dessa rodada, o Estado do Amapá foi incorporado efetivamente na recente fase de investigação (fase de exploração) de novas e viáveis reservas de hidrocarbonetos na costa brasileira. Todavia, em virtude do desconhecimento da atividade de exploração petrolífera, da importância ambiental e do pouco conhecimento sobre os processos e recursos naturais da foz do Amazonas, configurou-se um quadro de inúmeras incertezas e expectativas quanto aos reais impactos e benefícios da atividade para o Estado do Amapá, principalmente na população local.

Por ser caracterizada como atividade potencialmente causadora de significativo impacto ambiental, a exploração petrolífera só poderá ser desenvolvida, mediante rigoroso processo de licenciamento ambiental, o qual é conduzido pelo Instituto Brasileiro do Meio Ambiente e dos Recursos Naturais Renováveis (IBAMA). Destaca-se que para a realização das atividades petrolíferas offshore (em áreas costeiras), são exigidas licenças ambientais distintas para as diferen- 
tes fases do empreendimento (BRASIL, 2011). Na fase atual de exploração, ou pesquisa, é necessária a emissão de uma Licença de Operação (LO) para a perfuração de poços, cujo principal documento exigido é o Estudo de Impacto Ambiental (EIA) e Relatório de Impacto Ambiental (RIMA), os quais devem ser apresentados e discutidos com a sociedade, por meio de consulta popular na forma de audiências públicas.

A consulta pública tem não só a finalidade de informar à sociedade sobre o empreendimento e seus impactos, como também de possibilitar que os tomadores de decisões fiquem cientes dos anseios, aspirações e dos receios dos cidadãos sobre os impactos provenientes do empreendimento. Dessa forma, é um importante instrumento que permite que a sociedade contribua efetivamente com o processo de licenciamento ambiental, ainda que seja objeto de críticas quanto à sua efetividade, como afirma Sanchez (2013). Para o autor, não se tem uma verdadeira participação popular nas audiências públicas, pois, ainda que participem, não tem poder de decisão, função essa atribuída exclusivamente ao órgão licenciador, o qual tem o pleno poder de acatar ou não as contribuições advindas da consulta pública. Nessa mesma linha, Silva e Silva (2014) advertem que as audiências públicas podem "acabar sendo um mero evento formal para se cumprir protocolos e rituais para a emissão o mais rápido possível da licença ambiental". Assim, as manifestações da sociedade podem não produzir efeito dentro do processo.

Sánchez (2013) apresenta alguns entraves de ordem prática que restringem a participação efetiva dos cidadãos em uma audiência, como: o tempo que as pessoas podem dedicar-se a leitura do conteúdo do EIA/RIMA e ao comparecimento ao evento, bem como a limitação intelectual para acessar o conteúdo apresentado. Seja pela necessidade de decodificar termos técnicos, assim como, pelo reduzido nível de compreensão do conteúdo por pessoas de baixa escolaridade ou analfabetos funcionais. Ainda assim, o autor destaca que a audiência pública é um avanço e uma conquista da sociedade, um espaço onde o indivíduo tem liberdade para manifestar-se livremente. O que assegura exercer sua cidadania e negociar diretamente com empreendedores, sem uma intermediação judicial (ASSUNÇÃO; BURSZTYN; ABREU, 2010).

Além disso, comumente a consulta é realizada de forma tardia no processo de licenciamento e a maior parte do público desconhece o projeto e seus impactos, ou seja, não dispõem de informações para debater e contribuir com o processo.

Nesse contexto, surgem diversas indagações quanto ao recente processo de licenciamento ambiental da exploração petrolífera na bacia da foz do Amazonas: a população estava informada e se apropriou sobre o conteúdo do EIA/RIMA? A participação popular em audiências públicas deu contribuições significativas para o processo de licenciamento? Responder essas indagações é que incentivaram a realização da pesquisa aqui apresentada, a qual teve por objetivo avaliar as contribuições da participação popular ao processo de licenciamento ambiental de exploração petrolífera. Especificamente na concessão da licença de operação de perfuração no bloco marítimo FZA-M-59 na Bacia da Foz do Amazonas, sob responsabilidade da empresa ENERGY DO BRASIL LTDA (BP). A pesquisa foi centrada na audiência pública realizada em Macapá no dia 13 de novembro de 2017, momento de apresentação e discussão do EIA/RIMA. Dessa forma, o presente estudo, de caráter exploratório, foi baseado na análise quanti-qualitativa da Ata Pública da referida audiência e parecer técnico emitido a seguir pelo órgão licenciador, ou seja, embasado na análise documental. Todavia, teve seu primeiro momento na revisão da literatura acerca da temática em discussão, seção a ser apresentada a se- 
guir, como referencial ou embasamento teórico da pesquisa.

\section{REFERENCIAL TEÓRICO}

\subsection{Processo de Licenciamento Ambiental da atividade petrolífera no Brasil}

A resolução Conama no $.237 / 97$, no art. $4^{\circ}$ estabelece que é de competência do IBAMA o licenciamento ambiental de empreendimentos e atividades com significativo impacto ambiental de âmbito nacional e regional. Sendo também de sua responsabilidade licenciar as atividades localizadas ou desenvolvidas conjuntamente no Brasil e em país limítrofe; no mar territorial; na plataforma continental; na zona econômica exclusiva; em terras indígenas ou em unidades de conservação do domínio da União (BRASIL, 1997).

Considerando que blocos da Foz do Amazonas estão localizados na zona econômica exclusiva (ZEE), o processo de licenciamento ambiental para a realização das atividades petrolíferas na região, assim como, o gerenciamento da audiência pública é de competência do IBAMA. Destaca-se que o processo de licenciamento ambiental das atividades e empreendimentos marítimos (offshore) do setor de petróleo é conduzido pela Coordenação e Gestão de Petróleo e Gás (CGPEG) da referida instituição.

\subsubsection{Licenças ambientais para exploração e produção de hidrocarbo- netos}

A Portaria MMA n 422 de 26 de outubro de 2011 dispõe sobre os procedimentos para o licenciamento ambiental federal de atividades e empreendimentos de exploração e produção de petróleo e gás natural no ambiente marinho e em zona de transição terra-mar (BRASIL, 2011). Para a execução das atividades, os empreendedores devem iniciar os procedimentos para o licenciamento junto ao IBAMA, onde são informadas as condições, restrições e medidas de controle ambiental estabelecidas para a execução do empreendimento. Por meio do Termo de Referência (TR) são estabelecidos o conteúdo mínimo e as orientações para elaboração dos estudos ambientais a serem apresentados no decorrer do processo.

De acordo com a portaria supracitada, o processo de licenciamento ambiental federal de atividades e empreendimentos de exploração e produção de petróleo e gás natural no ambiente marinho apresenta uma gama de licenças e estudos que ficam sujeitos à aprovação do órgão licenciador, como mostrado no Quadro 1. 
Quadro 1- Licenças para exploração e produção de petróleo e gás natural no ambiente marinho.

\begin{tabular}{|l|}
\hline LICENÇA \\
Licença de Pesquisa Sís- \\
mica - LPS
\end{tabular}

Licença de Operação LO para perfuração de poços

Licença Prévia-LP:

Licença de instalação LI

Licença de OperaçãoLO

Fonte: BRASIL (2011).
ESTUDO

Estudo Ambiental de Sísmica - EAS (Profundidade superior a 200m) ou Informações Complementares ao Plano de Controle Ambiental de Sísmica - PCAS;

Estudo Ambiental de Perfuração - EAP (Profundidade superior a 1000 metros, a mais de 50 quilômetros de distância da costa)

Estudo Prévio de Impacto Ambiental/Relatório de Impacto Ambiental - EIA/RIMA,

Acompanhado das informações e documentos adicionais estabelecidos no processo de concessão das licenças anteriores,

Acompanhado das informações e documentos adicionais estabelecidos no processo de concessão das licenças anteriores,

\begin{tabular}{|l|lr|}
\hline ATIVIDADE & PRAZO \\
\hline Pesquisas sísmicas & $\begin{array}{l}\text { Prazos } \\
\text { mos: 5 anos }\end{array}$ \\
\hline Perfuração de poços & $\begin{array}{l}\text { Prazos } \\
\text { mos: 10 } \\
\text { anos. }\end{array}$ & (déxi- \\
\hline $\begin{array}{l}\text { Localização e con- } \\
\text { cepção do empreen- } \\
\text { dimento }\end{array}$ & $\begin{array}{l}\text { Prazos mos: 5 } \\
\text { máxi- } \\
\text { anos }\end{array}$ \\
\hline $\begin{array}{l}\text { Instalação do em- } \\
\text { preendimento ou } \\
\text { atividade }\end{array}$ & $\begin{array}{l}\text { Prazos } \\
\text { mos: 6ráxi- } \\
\text { anos }\end{array}$ \\
$\begin{array}{l}\text { Operação do empre- } \\
\text { endimento ou ativi- } \\
\text { dade }\end{array}$ & $\begin{array}{l}\text { Prazos } \\
\text { mos: 10 } \\
\text { anos }\end{array}$ \\
\hline
\end{tabular}

A primeira licença a ser obtida prevista na Portaria supracitada corresponde a Licença de Pesquisa Sísmica (LPS), a qual autoriza a coleta de dados sísmicos dentro do bloco. A segunda licença é descrita no capítulo III da mesma Portaria e se refere à autorização para a perfuração de poços, denominada de Licença de Operação (LO). Na fase inicial, ela autoriza as atividades de perfuração de poços no ambiente marinho para fins de estudo. Destaca-se que é neste estágio que se encontram as atividades de exploração petrolífera na costa do Estado do Amapá, ou seja, a referida audiência objeto da presente análise visou subsidiar a decisão sobre a licença ambiental para a perfuração de poços no bloco exploratório FZA-M-59.

Uma das condições para liberação das licenças ambientais e a apresentação de estudos ambientais, os quais abordam os estudos de base ou de caracterização do ambiente que pode ser impactado e assim subsidiar a avaliação dos impactos e as medidas de mitigação. Assunto que será abordado na próxima seção.

\subsubsection{Estudos ambientais}

Para empreendimentos que desempenham atividades ou obras que tenham o potencial de causar degradação significativa ao meio ambiente a Constituição Federal em seu art. 225, parágrafo $1^{\circ}$, inciso IV exige, na forma da lei, a realização de estudos ambientais e sua devida publicidade. Segundo Sánchez (2013) os estudos técnicos necessários ao licenciamento ambiental são definidos pelo órgão licenciador.

Especificamente em relação à exploração petrolífera, a partir da edição da PORTARIA MME/MMA n ${ }^{\circ}$ 198/2012, ficou estabelecido que em processos de licenciamentos ambientais que visem obter licenças para a exploração de petróleo e/ou gás natural em áreas sedimentares, o primeiro estudo que deve ser elaborado é o Estudo Ambiental de Área Sedimentar (EAAS), sendo esse de responsabilidade do Ministério de Minas e Energia, que pode executa-lo direta ou indiretamente, devendo inclusive, prever consultas públicas no processo (BRASIL, 2012).

O EAAS é o instrumento central do processo de Avaliação Ambiental de Área Sedimentar - AAAS e subsidia ou condiciona a liberação de outorga de blocos exploratórios de petróleo e gás natural localizados nas bacias sedimentares marítimas e terrestres para os leilões de concessão de exploração por parte da ANP. Por estar vinculado a uma portaria interministerial, sua execução é de responsabilidade conjunta dos Ministérios de Minas e Energia e; do Meio Ambiente. Um dos, senão principal produto do EAAS é a sugestão de classificação da área 
sedimentar quanto à sua aptidão para outorga de blocos exploratórios, que podem ser: áreas aptas, não aptas ou com indicação de moratória (BRASIL, 2012).

As áreas aptas são aquelas que a partir da AAAS são identificadas como compatíveis com atividades e empreendimentos de exploração e produção de petróleo e gás natural mediante a utilização das melhores práticas da indústria. Já as áreas não aptas são aquelas que os ativos ambientais são altamente relevantes e cuja necessidade de conservação são incompatíveis com os impactos e riscos associados à atividade petrolífera. Por sua vez, as áreas em moratória são aquelas que apresentam importantes lacunas de conhecimento científico ou relevantes conflitos de uso do espaço e dos recursos socioambientais, dependendo de aprofundamento de estudos e desenvolvimento tecnológico de alternativas ambientalmente mais adequadas para decisão quanto à aptidão para exploração de hidrocarbonetos (BRASIL, 2012).

A Portaria menciona que o "EAAS terá uma versão inicial, a qual será submetida à consulta pública e uma versão consolidada, denominada EAAS consolidado, que incluirá as contribuições recebidas", o que possibilita a efetiva participação social no processo. A análise prévia das áreas ambientais a serem ofertadas pela ANP nas rodadas de licitações desde 2004 é de responsabilidade do grupo de trabalho interinstitucional de atividade de exploração e produção de óleo e gás. No caso em análise no presente estudo, ou seja, a exploração petrolífera na foz do Amazonas, o parecer técnico GTPEG no 01/2013 ressalta que os setores SFZA-AR1 e SFZA-AP1 apresentam "significativas lacunas de conhecimentos sobre o ambiente da região" e o "litoral é de alta sensibilidade ambiental", ou seja, indicando que bacia se enquadrava na classificação de áreas em moratória. Todavia, ainda assim foi considerada como apta a ser leiloada (BRASIL, 2013). Talvez essa tenha sido a motivação para exigir um EIA/RIMA e não um Estudo Ambiental de Perfuração (EAP) para subsidiar a expedição da licença de operação (LO), como previsto no quadro 1.

A Portaria MMA n ${ }^{\circ}$ 422/2011 em seu art. $1^{\circ}$ e inciso IV apresenta a definição de estudos ambientais com foco no setor de petróleo:

[...] são todos e quaisquer estudos relativos aos aspectos ambientais relacionados a uma atividade ou empreendimento, apresentados como subsídio para a análise da licença requerida, com escopo e conteúdo adequados à complexidade da avaliação dos impactos e riscos envolvidos no projeto, tais como: Estudo Prévio de Impacto Ambiental-EIA, Estudo Ambiental de SísmicaEAS, Estudo Ambiental de Perfuração-EAP, Estudo Ambiental de Teste de Longa DuraçãoEATLD;

Com o intuito de instruir os empreendedores no processo de licenciamento ambiental foram estabelecidos variados estudos ambientais por diferentes instrumentos legais, tanto federais quanto estaduais e municipais. O quadro 2 apresenta os estudos que são exigidos para o setor do petróleo com foco na exploração e produção. 
Quadro 2 - Tipos de estudos ambientais previstos para o licenciamento do setor de petróleo.

\begin{tabular}{|c|c|c|}
\hline DENOMINAÇÃO & REFERÊNCIA & APLICAÇÃO \\
\hline $\begin{array}{l}\text { EIA - Estudo de Impacto Ambiental e } \\
\text { RIMA - Relatório de Impacto ambiental }\end{array}$ & $\begin{array}{l}\text { Res. Conama 1, de } \\
23 / 1 / 1986\end{array}$ & $\begin{array}{l}\text { Licenciamento de atividades modificadoras do meio ambiente } \\
\text { exemplificadas no Art. } 2^{\circ} \text { da resolução. }\end{array}$ \\
\hline PCA- Plano de Controle Ambiental & $\begin{array}{l}\text { Res. Conama 23, de } \\
7 / 12 / 1994\end{array}$ & $\begin{array}{l}\text { Obtenção de licença de operação para produção de petróleo e } \\
\text { gás. }\end{array}$ \\
\hline RCA - Relatório de Controle Ambiental & $\begin{array}{l}\text { Res. Conama 23, de } \\
7 / 12 / 1994\end{array}$ & $\begin{array}{l}\text { Obtenção de licença previa para perfuração de poços de petró- } \\
\text { leo. }\end{array}$ \\
\hline EVA - Estudo de Viabilidade Ambiental & $\begin{array}{l}\text { Res. Conama 23, de } \\
7 / 12 / 1994\end{array}$ & $\begin{array}{l}\text { Obtenção de licença prévia para pesquisa de viabilidade eco- } \\
\text { nômica de um campo petrolífero. }\end{array}$ \\
\hline RAA - Relatório de Avaliação Ambiental & $\begin{array}{l}\text { Res. Conama 23, de } \\
7 / 12 / 1994\end{array}$ & $\begin{array}{l}\text { Obtenção de licença previa para perfuração de poços de Pe- } \\
\text { tróleo. }\end{array}$ \\
\hline Plano de Emergência Individual & $\begin{array}{l}\text { Res. Conama 293, de } \\
12 / 12 / 2001\end{array}$ & $\begin{array}{l}\text { Licenciamento de portos organizados, instalações portuárias } \\
\text { ou terminais, dutos, plataformas e instalações de apoio. }\end{array}$ \\
\hline RAP - Relatório Ambiental Preliminar & $\begin{array}{l}\text { Res. Conama 316, de } \\
29 / 10 / 2002\end{array}$ & $\begin{array}{l}\text { Para instruir requerimentos de licenciamento ambiental de em- } \\
\text { preendimentos que possam causar impactos significativos. }\end{array}$ \\
\hline
\end{tabular}

Fonte: Adaptado de Sánchez, 2013.

Quadro 2 - Tipos de estudos ambientais previstos para o licenciamento do setor de petróleo (continuação).

EAS - Estudo Ambiental de Sísmica e

RIAS - Relatório de Impacto Ambiental de Res. Conama 350, de 06/06/2004

Sísmica (inserido pelos autores)

Estudo Ambiental de Teste de Longa Dura-

ção - EATLD e Relatório de Impacto Ambiental de Teste de Longa Duração - RIATLD

(inserido pelos autores)

Estudo Ambiental de Perfuração - EAP e

Relatório de Impacto Ambiental de Perfura- Port. MMA 422, de 26/10/2011

ção - RIAP; (inserido pelos autores)

Fonte: Adaptado de Sánchez, 2013.
Obtenção da Licença de Pesquisa SísmicaLPS, para aquisição de dados sísmicos marítimos e em zonas de transição.

Obtenção da licença do Teste de Longa Duração-TLD. Tem como finalidade principal a obtenção de dados e informações para conhecimento dos reservatórios.

Obtenção da licença para perfuração de poços no ambiente marinho.

Por sua vez, o órgão licenciador dever tornar público tais estudos. No caso de licenciamento submetidos a EIA/RIMA, uma das formas de publicidade são as audiências públicas que tem o objetivo tanto de informar a sociedade, quanto obter contribuições para o processo de tomada de decisão.

\subsection{Audiências públicas}

\subsubsection{Definições, conceitos e importância das audiências públicas}

Segundo a Resolução Conama no 09/1987 a realização de audiência pública no processo de licenciamento ambiental poderá ser solicitada pelo Ministério Público, por entidade civil, ou por 50 (cinquenta) ou mais cidadãos junto ao órgão licenciador. De acordo com o seu Art. $3^{\circ}$, esse tipo de consulta pública deve ser conduzido por um representante do órgão licenciador que, "após exposição objetiva do projeto e do seu respectivo RIMA, abrirá as discussões com os interessados presentes” (BRASIL, 1987).

Para o MMA a audiência pública é uma das formas de consulta pública prevista nos casos de EIA/RIMA. Tem por objetivo informar a sociedade e obter contribuições para o processo de tomada de decisão do órgão ambiental, podendo ser presencial ou não (BRASIL, 2011).

Sánchez (2013) ressalta que as audiências públicas ambientais são eventos formais convocados e conduzidos por um ente governamental. Além disso, são abertos aos cidadãos e com dinâmica e regras previamente estabelecidas, tendo como finalidade realizar um debate público sobre um determinado projeto e seus impactos.

A participação pública na AIA é comumente considerada como forma de promover políti- 
cas democráticas e tornar a AIA mais eficaz. Todavia, há pouca reflexão sobre o significado, os objetivos e o nível adequado de representação da participação pública no processo (GLUCKER, et. Al, 2013).

O termo participação pode ser encontrado na literatura como participação cidadã, pública e algumas vezes como participação popular e; apesar dos diferentes conceitos apresentados, principalmente com discussões no campo da teoria da ciência política, o cerne de participação do indivíduo é a mesmo e relaciona-se como sua manifestação e seu poder (FARIAS; SILVA, 2017). Os mesmos autores destacam que a importância atribuída à participação do público é reconhecida não apenas como um princípio em si, mas consensuada de que esta participação seja fundamental para uma avaliação ambiental efetiva.

Nesse aspecto, ainda que existem diferentes conceitos, formas de abordagem e um amplo espectro de discussão sobre a participação social ou cidadã no campo das ciências políticas. Este não será abordado no presente artigo, pois se escopo principal é o de avaliar a contribuição da participação pública ao processo de AIA.

Sánchez (2013) ressalta que a participação da sociedade civil, como as ONGs ambientalistas, entidades profissionais, associações de moradores, entre outras enriquecem os debates públicos, uma vez que assumem o papel de público esclarecido. Todavia, o mesmo autor apresenta uma síntese das deficiências nas audiências públicas, como: i. a dinâmica adotada favorece um clima de confronto; ii. ocorrer muito tarde no processo de AIA; iii. a maior parte do público dispõe de pouquíssimas informações sobre o projeto e seus impactos; iv. os processos de informação pública que deveriam preceder a audiência são deficientes e; v. o uso frequente de argumentos de cunho técnico-científicos, entre outros.

Negev et al. (2013) também oferecem críticas a esse processo de participação social na AIA, consideram que as audiências têm mais o intuito de direcionar o público que oferecer oportunidades reais de participação no processo e na tomada de decisão.

De acordo com Sánchez (2013) uma audiência pública nunca é deliberativa em virtude de nada ser votado ou decidido, mas o licenciador poder ser influenciado pelos debates ou questionamentos. Relata diferentes casos em que a população influenciou a tomada de decisão de modo a modificar ou até mesmo suspender um projeto.

Mesmo com seus entraves, a realização de audiência pública no processo de licenciamento ambiental é um importante meio pelo qual o cidadão pode influenciar na tomada de suas decisões. Contudo, o envolvimento da população nas etapas pós-aprovação é essencial para garantir o efetivo cumprimento das promessas contidas no EIA/RIMA e dos compromissos assumidos por meio da licença ambiental.

Pondera-se que existem alguns estudos desenvolvidos sobre a contribuição da audiência ao processo de licenciamento ambiental no âmbito nacional e local os quais apontam para a baixa efetividade desse instrumento de participação social. Ao analisarem a participação social no licenciamento ambiental das atividades de exploração e produção (E\&P) de petróleo na Bacia de Campos (RJ), Goulart e Amaral (2009) caracterizaram a participação social no processo de licenciamento como de "pouca efetividade" e atribuem tal fato, às dificuldades relacionadas à comunicação da informação ambiental e à conscientização do papel social.

Martini e Souza-Lima (2015) a partir de um estudo de caso de licenciamento ambiental de uma estrutura condominial portuária em Paranaguá (PR), concluíram que a audiência pública além de não garantir, ainda negou espaços para o exercício da cidadania ambiental. Apontam que "há um evidente descolamento entre a previsão normativa e a prática" no que se refere às 
audiências públicas. Destacam como possíveis causas: a baixa participação social por meio de intervenções escritas e orais; o alijamento do debate das classes menos favorecidas e; o fato de que o palco da audiência é dominado pelo empreendedor e seus consultores.

Assunção, Bursztyn e Abreu (2010) avaliaram o processo de participação social em quatro tipos de empreendimentos diferentes submetidos ao processo de avaliação de impacto ambiental no estado da Bahia e observaram que esses espaços de participação "têm sido utilizados muito mais para expor as carências das comunidades e reivindicar medidas de inclusão social, do que para discutir os impactos ambientais da área em que será instalado o empreendimento”.

Já Almeida, Gonçalves e Farias (2018), analisaram a participação pública em processos de licenciamento ambiental no triângulo mineiro e concluíram em um estudo de caso que embora a participação popular tenha sido alta, não agregou nenhuma contribuição para o processo decisório.

Em um contexto mais regional, Silva e Silva (2014) analisaram o processo de participação popular nas audiências públicas do Aproveitamento Hidrelétrico (AHE) Ferreira Gomes no município homônimo no Estado do Amapá para a concessão da Licença Prévia do projeto. Com base na análise de três audiências realizadas nos municípios de Ferreira Gomes, Porto Grande e Macapá, concluíram que quantitativamente a participação popular foi significativa, mas qualitativamente não foi efetiva em virtude da ausência de conhecimento e informação em nível pertinente por parte da população para argumentar e questionar em relação aos impactos do empreendimento.

\subsubsection{O regulamento da audiência pública}

Segundo a Resolução Conama no 09/1987, as audiências devem ser constituídas por uma mesa diretora e uma plenária. A mesa é composta por um presidente, sendo esse um representante do órgão licenciador, um secretário executivo e por autoridade federais, estaduais e municipais, a critério do presidente da mesa. Cabe ao secretário executivo a coordenação do registro dos participantes da audiência pública, em lista de presença, contendo nome, número do documento de identidade, telefone e instituição que representa, assim como; é de sua responsabilidade a preparação da ata. Os documentos recebidos no decorrer da audiência pela mesa diretora devem ser juntados ao processo administrativo de licenciamento ambiental do empreendimento (BRASIL, 1987).

As audiências públicas seguem um ritual pré-estabelecido que é fornecido aos participantes no credenciamento na forma de um regulamento. No caso estudado, o primeiro procedimento realizado por todos os participantes foi a assinatura na lista de presença, sendo ofertada uma lista complementar para autoridades e representantes de instituições, o que possibilitou o registro e o seu anúncio durante a realização do evento.

A audiência teve início com uma abertura oficial, ou seja, execução do Hino Nacional com posterior pronunciamento do presidente da mesa diretora, o qual apresentou os objetivos e a sequência dos trabalhos da consulta pública. Em seguida foi dada a palavra a um representante do órgão licenciador, que teve 20 minutos para fazer sua explanação sobre o andamento do processo de licenciamento do empreendimento. Na sequência, um representante da empresa dispôs também de 20 minutos para apresentar o RIMA.

A equipe técnica responsável pela elaboração do EIA/RIMA teve o prazo de 40 minutos para realizar a exposição técnica sobre o estudo desenvolvido, sendo exigida uma linguagem 
clara e objetiva. Posteriormente foram abertas as inscrições para manifestações escritas e orais no mesmo momento que foi dado um intervalo de 30 minutos. A seguir, iniciou-se a etapa de debates, com perguntas e respostas, processo conduzido pelo presidente da mesa. As perguntas escritas foram as primeiras a serem respondidas, desde que o autor estivesse presente, sendo admitida a possibilidade de sua manifestação de forma oral em até 3 minutos, caso a resposta dada não o tivesse satisfeito.

As respostas deveriam durar no máximo três minutos, mas o presidente poderia prorrogar esse tempo. Os questionamentos ou eventuais esclarecimentos que não fossem possíveis de serem atendidos teriam um prazo de 15 dias para serem enviados ao IBAMA, que deveria providenciar o respectivo encaminhamento aos interessados. Por fim, foram feitas as considerações finais pelo presidente da mesa e a audiência foi encerrada.

Todos os documentos entregues por ocasião da audiência pública foram anexados ao processo, assim como os registros de gravações. Por um prazo de 10 dias úteis, a contar da data da realização da audiência, poderiam ser encaminhados comentários, manifestações e sugestões ao órgão licenciador, anexando-os ao processo administrativo de licenciamento do empreendimento.

\section{METODOLOGIA}

A primeira etapa da pesquisa se concentrou na revisão bibliográfica, o que permitiu a consolidação do conhecimento sobre temas e conceitos chaves relacionados com a temática, e o que possibilitou a estruturação do referencial teórico inerente a pesquisa, bem como o levantamento do estudo da arte, ou seja, de trabalhos anteriores sobre o mesmo foco e metodologia empregada nesses. Esse estágio permitiu também estruturar a metodologia a ser empregada na pesquisa, a qual foi baseada na pesquisa documental, tendo como fontes de consulta $\mathrm{O}$ EIA/RIMA apresentado ao IBAMA pela empresa BP Energy do Brasil (AECOM, 2017). A ata da audiência pública ${ }^{3}$ realizada em 13/11/2017 no auditório do SEBRAE, Macapá-AP, bem como o seu caderno de presença. Além de outros documentos relacionados com o processo de licenciamento como o parecer técnico emitido pelo IBAMA após as audiências.

O caderno de presença da audiência pública permitiu a análise quantitativa dos participantes na audiência, os quais foram agrupados por categorias. Já com base na ata foram extraídos os principais questionamentos e manifestações objeto de discussão no evento, bem como os responsáveis por tais contribuições ao processo. Essas informações foram tratadas e verificadas se estavam dentro dos assuntos tratados no EIA/RIMA, no sentido de avaliar se os participantes teriam tomado conhecimento do empreendimento antes da audiência. Por fim, verificou-se se as contribuições advindas da audiência foram utilizadas no parecer técnico emitido pelo IBAMA após a referida audiência. Dessa forma, permitindo avaliar se a audiência pública trouxe contribuições efetivas ao processo de licenciamento e influenciando a tomada de decisão.

\footnotetext{
${ }^{3}$ A audiência pública foi realizada no dia 13 de novembro de 2017 no Auditório do SEBRAE, situado na Av. Ernestino Borges, 740, Laguinho - Macapá/AP início às quatorze horas e um minuto e finalizou as dezenove horas e vinte e sete minutos, ou seja, teve a duração de cinco horas e vinte e seis minutos.
} 


\section{RESULTADOS E DISCUSSÕES}

\subsection{Identificação do público presente na audiência pública}

Tendo como fonte os cadernos de presença da audiência (BRASIL, 2017a) foi possível analisar o público presente. Tanto os que se manifestaram (ativos) quanto os que apenas compareceram (passivos) sendo registrada a presença de 319 pessoas. A maior participação e que correspondeu a 48,6\% foi do setor educacional, ou seja, acadêmicos, professores ou funcionários de instituição de ensino. A seguir, 21\%, foram de participantes vinculados a empresas privadas. Tem-se ainda 15,7\% de funcionários de órgãos públicos, 3,8\% eram membros de ONG'S e, 1,9\% membros de associações ou sindicatos. Cerca de $9,1 \%$ foram classificados como outros, já que que não identificaram sua instituição/ocupação. Por sua vez, não se teve o registro de participação da classe política na audiência (Gráfico 1).

Gráfico 1- Análise do público conforme cadernos de presença da Ata da audiência pública sobre o licenciamento ambiental da exploração petrolífera (perfuração de poço) do Bloco FZA - M59.

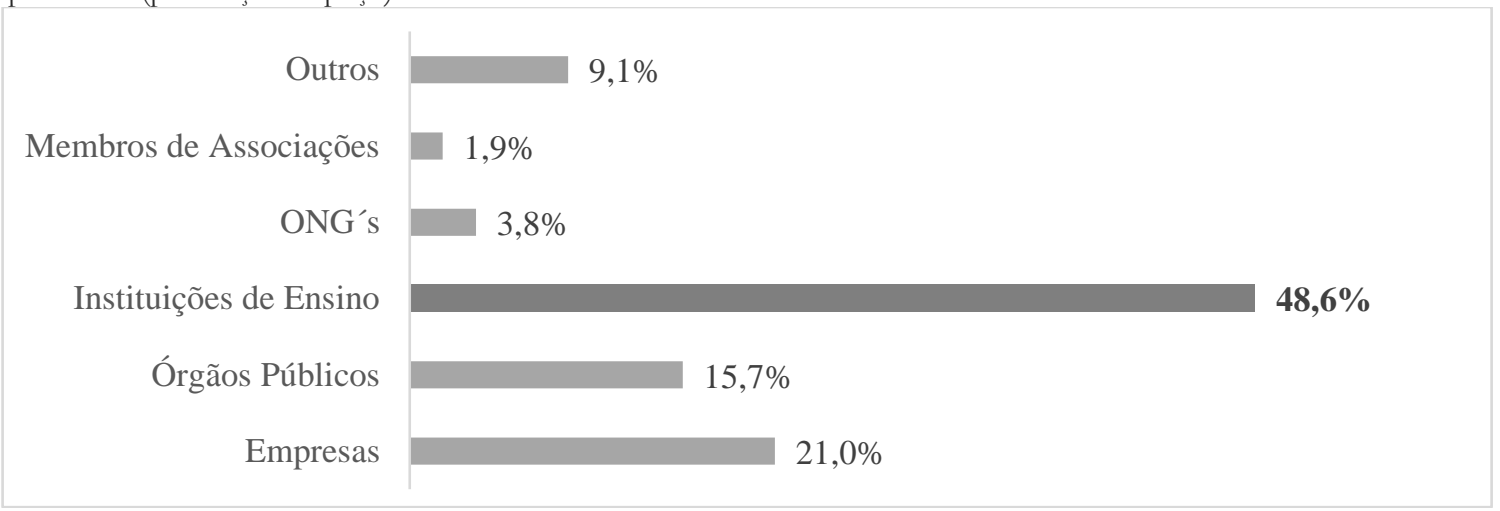

Fonte: Elaborado pelos autores com base na Ata da Audiência Pública (BRASIL, 2017a, b).

Com base nos números obtidos pode se inferir que grande parte das pessoas presentes no evento teriam grau de instrução suficiente para contribuir positivamente com o processo de licenciamento, sobretudo, pelo predomínio da classe acadêmica. Por outro lado, também chama a atenção a baixa participação de integrantes do setor público e político.

Já com base nas informações apresentadas na ata da audiência pública foi possível identificar, organizar, contabilizar e dividir os participantes que nela se manifestaram nas seguintes categorias: Organizações Governamentais (OG); Organizações Não Governamentais (ONG’s) e cidadão. Dentre as 319 pessoas presentes, cerca de $9 \%$ do público, ou seja, 28 pessoas se manifestaram por uma ou mais vezes, o que totalizou 47 participações, sendo 22 de cidadãos, três pessoas ligadas a organizações governamentais e três ligadas a organizações não governamentais (Gráfico 2).

É importante ressaltar que a categoria cidadão representa todos os indivíduos que não se encaixam nas outras duas categorias utilizadas, ou seja, é formada por acadêmicos, pesquisadores, professores e as demais pessoas que não tiveram sua instituição/ocupação identificada na ata ou no caderno de presença, mas que se manifestaram, tanto para fazer questionamentos quanto para pedir esclarecimentos ou tirar suas dúvidas.

Gráfico 2- Participação por grupos na audiência pública de Macapá sobre o licenciamento da exploração petrolífera (perfuração de poço) no Bloco FZA - M 59. 


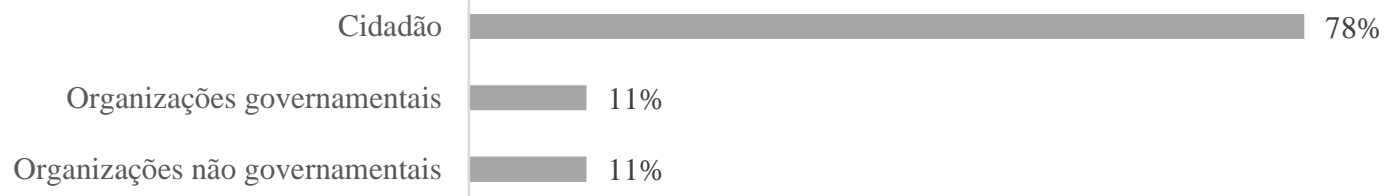

Fonte: Elaborado pelos autores com base na Ata da Audiência Pública (BRASIL, 2017a, b).

Do ponto de vista quantitativo a participação do público foi baixa, apenas $9 \%$ dos presentes se manifestaram, tendo a categoria cidadão alcançado o maior percentual de intervenções: $78 \%$, o que a princípio evidenciaria uma maior contribuição por essa categoria.

\subsection{Perguntas, questionamentos e manifestações realizadas na audiên- cia pública}

Como já mencionado, $9 \%$ do público presente na audiência pública se manifestou uma ou mais vezes. Foram registradas na ata 43 perguntas (24 escritas e 19 orais) e cinco "desabafos" o que totalizaram 47 participações ativas, das quais $74 \%$ estavam relacionadas com o RIMA (Quadro 3). Ressalta-se que na fase de perguntas orais alguns participantes além de questionarem, também manifestavam seus anseios e aspirações sobre o empreendimento, o que elevou o número de temas/assuntos abordados.

Quadro 3- Participação ativa da população na audiência pública de Macapá sobre o licenciamento da exploração petrolífera (perfuração de poço) no Bloco FZA - M 59.

\begin{tabular}{|c|c|c|c|c|}
\hline \multicolumn{5}{|c|}{ PERGUNTAS E DESABAFOS } \\
\hline Pessoas presentes & Pessoas partici- & \multicolumn{2}{|c|}{ Referente ao EIA/RIMA } & Total de Participações \\
\hline 319 & 28 & SIM & $\mathrm{NÃO}$ & \multirow[t]{2}{*}{47} \\
\hline \multicolumn{2}{|c|}{ Percentual de Participaccões } & 35 & 12 & \\
\hline \multicolumn{2}{|c|}{$9 \%$} & \multicolumn{2}{|c|}{ Referente ao EIA/RIMA } & $74 \%$ \\
\hline
\end{tabular}

Fonte: Elaborado pelos autores com base na Ata da Audiência Pública (BRASIL, 2017a, b).

Para facilitar a análise do conteúdo da ata da audiência pública (BRASIL, 2017b) foram elaboradas duas tabelas, a primeira contendo a síntese das perguntas, questionamentos e manifestações classificadas dentro do conteúdo do RIMA e; a segunda apresentando o conteúdo fora do contexto do RIMA, sendo que ambas estão divididas por categorias, temas e síntese da participação. É importante ressaltar que apenas as participações mais "significativas" estão expostas nos quadros a seguir.

De acordo com os quadros 4 e 5 verifica-se uma diversidade de temas abordados pelas três categorias de participantes. Isto demostra que a participação popular foi relevante no sentido de a sociedade apresentar seus anseios, aspirações e buscar esclarecimentos sobre o empreendimento. Ao se analisar as contribuições pelos temas abordados por cada categoria, pode ser constatado que a categoria ONG's apropriou-se apenas de dois temas, sendo ambos de cunho estritamente ambiental, um com foco nos Corais da Amazônia e o outro no potencial de novas espécie na região, o que pode evidenciar certo desinteresse dessa categoria com as questões mais de cunho social, como o desenvolvimento da região e com a qualidade de vida da população local. 
Quadro 4 - Síntese das perguntas, questionamentos e manifestações dentro do conteúdo do RIMA do licenciamento da exploração petrolífera (perfuração de poço) no Bloco FZA - M 59.

\begin{tabular}{|c|c|c|}
\hline CATEGORIA & TEMA & SÍNTESE DAS PERGUNTAS, QUESTIONAMENTOS E MANIFESTAÇÕES \\
\hline \multirow{8}{*}{ Cidadão } & $\begin{array}{l}\text { Unidade de perfuração } \\
\text { ENSCO DS-9 (navio- } \\
\text { sonda) }\end{array}$ & Perguntou sobre a idade do navio-sonda e a espessura de suas chapas. \\
\hline & $\begin{array}{l}\text { Modelagens matemáti- } \\
\text { cas de dispersão do } \\
\text { óleo. }\end{array}$ & $\begin{array}{l}\text { Manifestou-se solicitando esclarecimentos sobre o período de monitoramento de três } \\
\text { parâmetros usados nas modelagens, sendo eles: vento, ondas e correntes marinhas. O } \\
\text { participante alegou ter conhecimento local e teria se surpreendido com os resultados } \\
\text { obtidos pela empresa. }\end{array}$ \\
\hline & Bases de apoio & $\begin{array}{l}\text { Questionamento sobre o porquê de a base de apoio não ser em Santana; } \\
\text { Questionou que seria possível preparar uma base em Santana, além disso, mencionou } \\
\text { que não são previstas bases para emergência no Amapá, sugerido que fosse pensado em } \\
\text { uma base com essa finalidade no Oiapoque. }\end{array}$ \\
\hline & $\begin{array}{l}\text { Descarte do cascalho } \\
\text { de perfuração }\end{array}$ & Pergunta escrita sobre a destinação dos cascalhos de perfuração. \\
\hline & Problemas sociais & $\begin{array}{l}\text { Manifesto sobre o inchaço populacional e problemas associados devido a geração de } \\
\text { expectativa, inclusive sobre a atividade de pesca. }\end{array}$ \\
\hline & $\begin{array}{l}\text { Expectativas sobre ge- } \\
\text { ração de emprego }\end{array}$ & $\begin{array}{l}\text { Pergunta sobre a utilização da mão de obra local no empreendimento; } \\
\text { Manifestação: "Devemos olhar para a população que está precisando de empregos"; } \\
\text { Manifestação: "Problema de desemprego principalmente para os jovens"; } \\
\text { Manifestação: "A pesca gera renda para o estado e gera mais empregos que as empresas } \\
\text { de petróleo que querem explorar a bacia da Foz do Amazonas"; } \\
\text { Manifestação: Mostrou preocupações em relação a chegada do empreendimento petro- } \\
\text { lífero no município do Oiapoque, não sendo contra, mas tem receio sobre os efeitos da } \\
\text { atividade na região. }\end{array}$ \\
\hline & Pesca & $\begin{array}{l}\text { Pergunta sobre as medidas compensatórias para os pescadores caso sejam afetados pelo } \\
\text { empreendimento; } \\
\text { Perguntou se os peixes que habitam as zonas costeiras não serão impactados em um } \\
\text { vazamento; } \\
\text { Manifestou preocupação em relação ao município de Oiapoque, já que vivem da pesca } \\
\text { e em caso de acidente a população seria prejudicada. }\end{array}$ \\
\hline & $\begin{array}{l}\text { Impactos ambientais } \\
\text { transfronteiriços }\end{array}$ & $\begin{array}{l}\text { Pergunta sobre quais iniciativas estão sendo realizadas para mitigar impactos no territó- } \\
\text { rio francês; } \\
\text { Pergunta sobre que medidas a BP adota neste tipo de caso de impactos transfronteiriços. }\end{array}$ \\
\hline
\end{tabular}

Fonte: Elaborado pelos autores com base na Ata da Audiência Pública (BRASIL, 2017a).

Quadro 4 - Síntese das perguntas, questionamentos e manifestações dentro do conteúdo do RIMA do licenciamento da exploração petrolífera (perfuração de poço) no Bloco FZA - M 59 (Continuação).

\begin{tabular}{|c|c|c|}
\hline \multicolumn{2}{|c|}{ CATEGORIA TEMA } & SÍNTESE DAS PERGUNTAS, QUESTIONAMENTOS E MANIFESTAÇÕES \\
\hline \multirow{3}{*}{$\begin{array}{l}\text { Organiza- } \\
\text { ções Gover- } \\
\text { namentais }\end{array}$} & $\begin{array}{l}\text { Confiabilidade dos da- } \\
\text { dos adotados }\end{array}$ & $\begin{array}{l}\text { Questionamento sobre os dados secundários que tratam das comunidades planctônicas } \\
\text { apresentados no RIMA, uma vez que não correspondem com a conclusão que a pesqui- } \\
\text { sadora fez dentro do estudo que elaborou. }\end{array}$ \\
\hline & Problemas sociais & $\begin{array}{l}\text { Perguntou se foi avaliado o aumento de consumo de drogas em função das alterações } \\
\text { socioeconômicas; } \\
\text { Manifestação sobre inchaço populacional e problemas associados devido a geração de } \\
\text { expectativa, inclusive de sobre pesca. }\end{array}$ \\
\hline & $\begin{array}{l}\text { Base de apoio e expec- } \\
\text { tativas de geração de } \\
\text { emprego }\end{array}$ & $\begin{array}{l}\text { Manifestação onde sugere que deveria ter um navio em Oiapoque como resposta e pre- } \\
\text { venção a possíveis a acidentes; } \\
\text { Indagação sobre a possibilidade de trazer a base da empresa para Macapá e Oiapoque } \\
\text { para auxiliar no desenvolvimento do estado, o que poderia contribuir com a geração de } \\
\text { emprego, renda e de negócios. }\end{array}$ \\
\hline \multirow{2}{*}{$\begin{array}{l}\text { Organiza- } \\
\text { ções não go- } \\
\text { vernamental } \\
\text { (ONG'S- } \\
\text { GREENPE- } \\
\text { ACE) }\end{array}$} & Corais da Amazônia & $\begin{array}{l}\text { Pergunta sobre o motivo pelo qual a pluma do Amazonas fui considerada apenas em } \\
\text { águas rasas, sendo que o parecer do IBAMA indica que ela chega a } 500 \mathrm{Km} \text { da foz; } \\
\text { Pergunta sobre o uso do dispersante COREXIT, prejudicial aos corais. }\end{array}$ \\
\hline & $\begin{array}{l}\text { Sensibilidade ambien- } \\
\text { tal e potenciais de no- } \\
\text { vas espécies }\end{array}$ & $\begin{array}{l}\text { Questionou se valia a pena o risco da exploração em virtude da sensibilidade ambiental } \\
\text { e dos potenciais de novas espécies da região, sugerindo o abandono dos planos de ex- } \\
\text { ploração em nome da segurança. }\end{array}$ \\
\hline
\end{tabular}

Fonte: Elaborado pelos autores com base na Ata da Audiência Pública (BRASIL, 2017a).

A categoria cidadão teve o maior número de participações, abordando diversos temas, entre eles: unidade de perfuração, modelagem matemática, bases de apoio, problemas sociais, expectativas sobre geração de emprego, pesca e possíveis impactos ambientais transfronteiriços. 
Os resultados demonstram de certa forma a iniciativa das pessoas em participar ativamente nas audiências públicas, seja fazendo questionamentos ou buscando esclarecer suas dúvidas, tanto sob o aspecto socioeconômico quanto ambiental. Por outro lado, esta mesma categoria (cidadão) foi a única que abordou temas aparentemente fora do conteúdo do RIMA, como: custos das audiências, corrupção dentro do IBAMA, criação de unidades de conservação e outros (Quadro 5). Por outro lado, evidencia que o ambiente das audiências públicas é um espaço democrático, onde todos podem falar e serem ouvidos, ainda que tenham por vezes, algumas participações vagas, contraditórias e/ou longe da realidade do projeto e que pouco ou nada contribuam com o processo de licenciamento.

Quadro 5 - Síntese das perguntas, questionamentos e manifestações fora do conteúdo do RIMA do licenciamento da exploração petrolífera (perfuração de poço) no Bloco FZA - M 59.

\begin{tabular}{|c|c|c|}
\hline CATEGORIA & TEMA & $\begin{array}{l}\text { SÍNTESE DAS PERGUNTAS, QUESTIONAMENTOS E MA- } \\
\text { NIFESTAÇÕES }\end{array}$ \\
\hline \multirow{6}{*}{ Cidadão } & Publicidade dos estudos & $\begin{array}{l}\text { Pergunta sobre os meios para se ter acesso e receber os estudos ambi- } \\
\text { entais. }\end{array}$ \\
\hline & Custos das audiências & Pergunta sobre quem pagou pela audiência e o transporte dos técnicos. \\
\hline & Corrupção dentro do IBAMA & $\begin{array}{l}\text { Pergunta sobre as medidas que o IBAMA adota para o controle de } \\
\text { corrupção. }\end{array}$ \\
\hline & Analistas do IBAMA do Amapá & $\begin{array}{l}\text { Manifestação: Afirmou que estava "pasmo por não haver analistas do } \\
\text { IBAMA do Amapá envolvidos no estudo e sobre a propriedade/co- } \\
\text { nhecimento que os analistas do Rio de Janeiro tinham sobre os aspec- } \\
\text { tos locais". }\end{array}$ \\
\hline & Criação de Unidades de Conservação & $\begin{array}{l}\text { Perguntou se a empresa estava considerando a criação de determinadas } \\
\text { unidades de conservação; }\end{array}$ \\
\hline & $\begin{array}{l}\text { Cumprimento das exigências do } \\
\text { IBAMA }\end{array}$ & $\begin{array}{l}\text { Perguntou se existe algum ponto ou aspecto exigido pelo órgão no pro- } \\
\text { cesso de licenciamento que a empresa tenha se negado a cumprir. }\end{array}$ \\
\hline
\end{tabular}

Fonte: Ata da audiência pública (BRASIL, 2017a).

Por outro lado, as pessoas ligadas a organizações governamentais apresentaram uma maior apropriação sobre os temas que abordaram, quase todos relacionados a esclarecimentos sobre os estudos ambientais para subsidiar o seguro licenciamento da atividade. Destaca-se desde a confiabilidade dos resultados apresentados no RIMA, quanto os possíveis problemas sociais, expectativas de geração de emprego e as bases de apoio. O que demonstra a atenção e preocupação do poder público quanto aos possíveis impactos socioambientais gerados com a atividade petrolífera.

\subsection{Contribuições efetivas da consulta pública ao processo de licencia- mento}

Para o levantamento das contribuições efetivas advindas da audiência pública realizada pela BP ENERGY DO BRASIL LTDA (BP), foi analisado o parecer técnico no 176/2018-COEXP/CGMAC/DILIC emitido em outubro de 2018 pelo IBAMA de Brasília, que abordou o EIA da atividade de perfuração da BP no bloco FZA-M-59 (BRASIL, 2018). Sendo esse, o primeiro parecer técnico destinado a empresa BP após a realização da audiência pública em Macapá.

O parecer técnico contempla um tópico específico para as contribuições de destaque oriundas das audiências públicas realizadas nos municípios de Belém (PA), Oiapoque (AP) e Macapá (AP) nos dias 9, 11, 13 de novembro de 2017, respectivamente. Por sua vez, ao longo do parecer é possível verificar temas que foram debatidos na audiência realizada em Macapá, visto 
que, o foco do presente trabalho são as contribuições dessa audiência.

Um dos assuntos mais recorrentes ao longo do parecer é o descarte dos cascalhos de perfuração. Esse tema é ressaltado no item II.3.2 do parecer que trata das "Condições para uso e Descartes de Fluidos de Perfuração, Fluidos Complementares e da Pasta de Cimento Previstas na Atividade de Perfuração". Para o IBAMA, as informações apresentadas no estudo foram consideradas insatisfatórias sendo solicitada complementação. Pondera-se que é possível que o questionamento derivado da audiência pública analisada tenha contribuindo com tal exigência de melhoria nos estudos ou planos de controle sobre esse impacto.

A atividade pesqueira foi um tema muito presente na audiência, sendo abordado no parecer, subitem II.8.2.1.1 sobre os "Cenários de Operação Normal da Atividade" no tópico denominado de impactos potenciais (IMP) 3 - "Interferência na Atividade Pesqueira Industrial". O estudo foi considerado atendido, mas com ressalvas, considerando a alta probabilidade de interação das embarcações pesqueiras com as de apoio, bem como, sobre a ausência de projeto de comunicação social que contemplasse todas a embarcações que poderiam ali trafegar.

Sobre a confiabilidade do estudo de modelagem hidrodinâmica para simular a trajetória de dispersão de óleo em caso de derramamento, a qual é abordada no subitem II.8.2.2.2 - Anexo B - "Modelagem Hidrodinâmica e Dispersão de Óleo". Foi ponderado na audiência de Macapá que os dados apresentados não representariam "bem a dinâmica costeira da região". O que demonstrou certa apropriação do estudo produzido e possível contribuição da audiência no sentido de reforçar ao órgão licenciador uma maior preocupação com esse risco em face das fragilidades dos estudos.

No tópico II.12 sobre "Análise de Gerenciamento de Risco" é levantada a questão dos recifes biogênicos ou "corais da Amazônia”, abordado exaustivamente pela ONG Greenpeace durante a audiência de Macapá. Tal preocupação expressa parece também ter motivado o IBAMA a solicitar em seu parecer uma reavaliação dos riscos para esses componentes de alto valor ambiental.

Já no tópico II.13, subtópico 7.1.2 que trata de "Procedimentos de Gerenciamento de Incidentes" é levantada a ausência de um acordo bilateral entre Brasil e França para atender possíveis acidentes com o derramamento de óleo, o que reduz drasticamente a eficiência do plano de emergência individual proposto no EIA/RIMA do empreendimento. Destaca-se que os resultados da modelagem de dispersão do óleo indicam que ele dificilmente tocaria a costa do Amapá em caso de derramamento, mas poderia atingir os outros países, o que suscitaria a necessidade de um acordo internacional. Esta situação foi bastante questionada e debatida na audiência de Macapá, o que também pode ter contribuído para reforçar a solicitação de um acordo internacional no parecer do órgão licenciador.

Ainda que Martini e Souza-Lima (2015) advirtam que o fato de a audiência pública não ter caráter deliberativo, facultando ao órgão licenciador que avalie as considerações emanadas das audiências, todavia, sem obrigação de levá-las em conta na decisão final acerca da expedição das licenças ambientais. A equipe do IBAMA dedicou cinco páginas (15 a 20) do parecer técnico para expor as participações que considerou de destaque das três audiências públicas. Para a análise do conteúdo elaborou-se um quadro com os temas e a síntese das participações (Quadro 6). 
Quadro 6 - Participações de destaque na audiência pública realizada em Macapá sobre o licenciamento da exploração petrolífera (perfuração de poço) no Bloco FZA - M 59.

\begin{tabular}{|l|l|}
\hline TEMAS & SÍNTESE DAS PARTICIPAÇÕES \\
\hline Meio socioeconômico & $\begin{array}{l}\text { A pesca artesanal poderá ser afetada, uma vez que a avaliação de impactos foi equivocada e insu- } \\
\text { ficiente. } \\
\text { Com a nova dinâmica econômica oriunda do empreendimento cria-se um cenário de expectativas, } \\
\text { tanto com a possibilidade da geração de emprego, quanto de um crescimento desordenado na } \\
\text { região. }\end{array}$ \\
\hline \multirow{3}{*}{ Os dados apresentados sobre o meio biótico geraram desconfiança quanto a forma de obten- } \\
ção/coleta. \\
Incerteza sobre quais grupos biológicos foram levantados a partir de dados primários. \\
$\begin{array}{l}\text { Importância das aves migratórias que se reproduzem na costa do Amapá. } \\
\text { Questionamentos sobre os estudos e projetos ambientais propostos e a participação de institui- } \\
\text { ções locais nestes; } \\
\text { Incorporação de técnicos locais nas análises. } \\
\text { Monitoramento dos projetos ambientais. } \\
\text { Publicidade dos projetos de monitoramento e acompanhamento de seus resultados pela popula- } \\
\text { ção. } \\
\text { O cascalho de perfuração será descartado no mar; }\end{array}$ \\
\hline Destinação dos resíduos & $\begin{array}{l}\text { Incerteza se o modelo hidrodinâmico havia levado em consideração as correntes marítimas da } \\
\text { Guiana. } \\
\text { Dúvida sobre a publicidade dos estudos de modelagem. }\end{array}$ \\
\hline Plano de emergência individual & Acordo transfronteiriço \\
\hline
\end{tabular}

Fonte: Parecer técnico no 176/2018-COEXP/CGMAC/DILIC (BRASIL, 2018).

Entre as contribuições consideradas no parecer ainda consta a realizada pelo Greenpeace, que durante a audiência levantou a questão dos "Corais da Amazônia" e protocolou o documento Of. 1/2018 (SEI 2174025) após a consulta pública. Tal documento fez com que o IBAMA solicitasse o posicionamento da empresa BP sobre as informações protocoladas.

Pelo apresentado ao longo do parecer técnico, já era esperado que em sua conclusão constasse que seriam necessárias mais informações e esclarecimentos adicionais para subsidiar o processo de licenciamento da atividade, o que realmente ocorreu e o IBAMA adiou a liberação da licença.

Ao se relacionar os assuntos registrados na ata da audiência e o considerado de destaque pelo órgão licenciador, verificou-se que poucas foram as participações diretamente vinculadas ao conteúdo do EIA/RIMA. Todavia, as que estavam relacionados foram de certa forma apropriadas no processo de licenciamento e parecem ter motivado algumas solicitações adicionais conforme parecer emitido pelo órgão licenciador, indicando certa contribuição da audiência ao processo. Logo, nota-se que a relevância das participações não está tão somente no debate sobre o conteúdo do EIA/RIMA, mas também no conjunto de fatores que rodeiam o empreendimento e não são contemplados no estudo e no relatório, mas que são suscitados e debatidos nas audiências pelas diversas categorias de participantes.

Por outro lado, há ressalvas com algumas participações sem relação a atividade, pois pouco contribuem com o processo de licenciamento, ou seja, não são efetivas, apenas mostram os anseios, expectativas, mas também o desconhecimento sobre o empreendimento e falta de apropriação dos estudos ambientais por parte dos participantes. Esse problema também é relatado por Bezerra (2011) que ressalta que em análise sobre audiência pública de licenciamento de infraestrutura de transmissão de energia que prevaleceram questionamentos sobre impactos socioeconômicos sem relação com o empreendimento. Tal questão pode apontar para a necessidade de uma preparação ou realização de audiências prévias diretamente com os principais atores envolvidos, no sentido de levar e qualificar a informação dos estudos, o que poderia contribuir com uma participação mais efetiva da sociedade no processo de licencia- 
mento, ainda que se questione se há interesse do empreendedor em realizar isso.

\section{CONSIDERAÇÕES FINAIS}

Considerando que apenas 9\% dos participantes da audiência pública apresentaram algum tipo de questionamento, manifestação ou desabafo sobre os estudos ambientais ou sobre o processo de licenciamento da exploração petrolífera na bacia da Foz do Amazonas (bloco FZA M59), admite-se como sendo uma participação ativa relativamente baixa. Um percentual quase 40\% menor que da média encontrada por Silva e Silva (2014) ao analisar o licenciamento ambiental de uma hidrelétrica no estado do Amapá. Destaca-se a categoria cidadão como a que mais participou ativamente da audiência, sendo a maior parte das manifestações relacionadas com o estudo ambiental apresentado, o que de certa forma indica uma apropriação de seu conteúdo e assim respondendo um dos questionamentos suscitados na introdução deste artigo. Resultado que de certa forma, contraria uma das possíveis deficiências das audiências públicas apontadas por Sanchez (2013), de que a maior parte do público teria poucas informações sobre o projeto e seus impactos.

Ademais, ao se avaliar a contribuição da audiência para o processo de licenciamento, pode se concluir nesse estudo pela sua efetividade. Verificou-se que algumas das manifestações e debates ocorridos na audiência pública de Macapá, tais como a questão dos impactos na pesca, as expectativas de emprego, desconhecimento sobre os corais da Amazônia, além da modelagem de possível derramamento de óleo e suas consequências para outros países foram questões contempladas com destaque no parecer técnico emitido pelo IBAMA. De tal forma que o influenciou o em sua decisão, deliberando por solicitar mais informações e esclarecimentos para subsidiar o processo de licenciamento ambiental para a exploração do bloco FZA-M-59 pela empresa BP. Assim, pelo menos neste estudo de caso, a conclusão foi distinta a de Goulart e Amaral (2009) que apontaram para uma baixa efetividade da audiência pública no processo de licenciamento ambiental de atividades petrolíferas na Bacia de Campos, bem como a de Silva e Silva (2014) sobre o licenciamento de empreendimentos hidrelétricos no Amapá.

Pondera-se que apesar de não ser um instrumento pronto, ou seja, que ainda carece de ajustes, evidencia-se que a audiência pública é um mecanismo de participação social importante e efetivo ao processo de licenciamento ambiental, pois além de levar a informação sobre o empreendimento e seus impactos à sociedade, também permite ouvi-la, inclusive inserindo aspectos ou impactos outros, por vezes, não contemplados nos estudos ambientais. Destacase, sobretudo, sua relevância ao fato de tornar possível que os cidadãos influenciem o tomador de decisão sobre a liberação de uma licença ambiental como afirma Sánchez (2013), contrariando os achados de Almeida, Gonçalves e Farias (2018) que pontuam que a participação social não agregou nada à tomada de decisão, bem como, de Marini e Souza-Lima (2015), cujos achados de sua pesquisa sobre a mesma temática indicam justamente o contrário: uma negação à cidadania ambiental.

Como foi ressaltado, esta importante etapa do processo de licenciamento ainda precisa maturar e isso passa por entraves que devem ser sanados. A realização desse estudo propiciou identificar alguns desses problemas e pontua duas importantes diretrizes que podem contribuir para melhorar a efetividade das audiências ao licenciamento, tais como:

- Realizar reuniões prévias com os diversos atores para a apresentação do empreendi- 
mento e do conteúdo do RIMA antes da realização das audiências públicas, corroborando

- Melhorar a divulgação do EIA/RIMA, bem como da realização das audiências públicas, de forma a estimular uma maior participação social no processo de licenciamento.

São estratégias que coadunam com as considerações de Goulart (2009) que considera como elemento fundamental na audiência pública a preparação previa dos atores sobre os estudos ambientais, o que permitiria uma argumentação mais qualificada e pertinente ao processo.

Com isso, seria possível ter uma divulgação mais eficiente dos estudos ambientais da avaliação dos impactos, o que aumentaria o nível de conhecimento das pessoas sobre o empreendimento e suas fases, assim como, elevaria o nível intelectual dos debates e o número de participações conscientes e efetivas, contribuindo sobremaneira para a segurança do processo de licenciamento ambiental.

\section{REFERÊNCIAS}

AECOM DO BRASIL LTDA. Relatório de Impacto Ambiental - RIMA: Atividade de perfuração marítima no bloco FZA-M-59, na bacia da Foz do Amazonas, mar. 2017, pag. 66. ALMEIDA, M. R. R.; GONÇALVES, P. V. S.; FARIAS, C. P; Participação públicas nos processos de licenciamento ambiental no triângulo mineiro. Revista Brasileira de Geografia Física. V. 11, 2. 2018.

ASSUNÇÃO, F. N. A; BURSTYN, M. A. A.; ABREU, T. L. M. Participação social na avaliação de impacto ambiental: lições da experiência da Bahia, Confins [Online], 10 | 2010, posto online no dia 28 novembro 2010.

BEZERRA, I. O. PARTICIPAÇÃO POPULAR NO LICENCIAMENTO AMBIENTAL para a instalação da rede de energia no município de Balsas - MA. Monografia de Especialização. Centro de Desenvolvimento Sustentável - Universidade de Brasília. 2011. 96p.

BRASIL. Lei $\mathbf{n}^{\mathbf{0}} \mathbf{6 . 9 3 8}$, de 31 de agosto de 1981. Dispõe sobre a Política Nacional do Meio Ambiente, seus fins e mecanismos de formulação e aplicação, e dá outras providências. 2019. Disponível em: <http://www.planalto.gov.br/ccivil_03/Leis/L6938.htm>. Acesso em: 06 fev. 2019.

BRASIL. Conselho Nacional do Meio Ambiente. Resolução Conama $\mathbf{n}^{\circ}$ 237, de 3 de dezembro de 1997. Dispõe sobre licenciamento ambiental; competência da União, Estados e Municípios; listagem de atividades sujeitas ao licenciamento; Estudos Ambientais, Estudo de Impacto Ambiental e Relatório de Impacto Ambiental. Diário Oficial [da] República Federativa do Brasil, Brasília, 02 de dez. 1997, Seção 1, p. 30841-30843. Disponível em: <http://www2.mma.gov.br/port/conama/legiabre.cfm?codlegi=237>. Acessado em: 06 fev. 2019.

BRASIL. Conselho Nacional do Meio Ambiente - CONAMA. Resolução CONAMA n ${ }^{\circ}$ 009, de 3 de dezembro de 1987. Dispõe sobre Audiência Pública referidas na resolução CONAMA no 001/86. 2019. Disponível em: < http://www.mp.go.gov.br/nat_sucroalcooleiro/Documentos/legislacao/Geral/est_imp_amb/eia3.pdf > Acessado em: 06 fev. 2019.

BRASIL. Constituição (1988). Constituição da República Federativa do Brasil: texto constitucional promulgado em 5 de outubro de 1988, com as alterações determinadas pelas Emendas Constitucionais de Revisão nos 1 a 6/94, pelas Emendas Constitucionais nos $1 / 92$ a 91/2016 e pelo Decreto Legislativo no 186/2008. - Brasília: Senado Federal, Coordenação de Edições Técnicas, p. 496. 2016. 
BRASIL. Ministério do Meio Ambiente - MMA. Portaria no 422, de 26 de outubro de 2011. Dispõe sobre procedimentos para o licenciamento ambiental federal de atividades e empreendimentos de exploração e produção de petróleo e gás natural no ambiente marinho e em zona de transição terra-mar. 2011. Disponível em: < https://www.mprs.mp.br/media/areas/ gapp/arquivos/atualizacao_intra/dou/port_422.pdf>. Acessado em: 06 fev. 2019.

BRASIL. Ministério de Minas e Energia; Ministério do Meio Ambiente- MME/MMA (Brasil). Portaria interministerial $\mathbf{n}^{\mathbf{0}}$ 198, 05 abril 2012. Dispõe sobre Avaliação Ambiental de Área Sedimentar. 2019. Disponível em: <http://www.mme.gov.br/documents/10584/904396/ Portaria_interminestral+198+de+05-04-2012+Publicado+no+DOU+de+09-04-2012/b29 49275-4e6b-417a-9462-b15431d9a4e6;jsessionid=DF158852B8E73D61F5D5143A073ED 202.srv155 >. Acessado em: 06 fev. 2019.

BRASIL. Grupo de Trabalho Interinstitucional de Atividades de Exploração e Produção de óleo e Gás. Parecer técnico GTPEG n⿳0 01/2013. Dispõe sobre Análise ambiental das áreas propostas para a $11^{\mathrm{a}}$ rodada de licitações da ANP-blocos exploratórios complementares. 2013. Disponível em: <http://rodadas.anp.gov.br/arquivos/diretrizes_ambientais/Parecer/Parecer_01-13.pdf > Acessado em: 06 fev. 2019.

BRASIL. Agência Nacional de Petróleo, Gás Natural e Biocombustíveis - ANP. 11a Rodada de Licitações de blocos. 2013. Disponível em: < http:/ / rodadas.anp.gov.br/pt/concessaode-blocos-exploratorios-1/11-rodada-de-licitacao-de-blocos >. Acessado em: 06 jan. 2019.

BRASIL. Instituto Brasileiro do Meio Ambiente e dos Recursos Naturais Renováveis IBAMA. Audiência pública COEXP/CGMAC/DILIC/IBAMA Nº 03/2017, 2017, Macapá. Ata...Macapá, 29 nov. 2017(a). Disponível em: <http://licenciamento.ibama.gov. br/Petroleo/Perfuracao/Perfuracao $\% 20-\% 20$ Bacia $\% 20 \mathrm{da} \% 20 \mathrm{Foz} \% 20 \mathrm{do} \% 20$ Amazonas $\%$

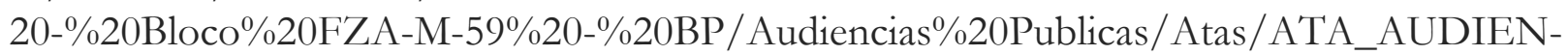
CIA_MACAPA.pdf > Acessado em: 06 fev. 2019.

BRASIL. Instituto Brasileiro do Meio Ambiente e dos Recursos Naturais Renováveis IBAMA. Cadernos de presença, Macapá, 13 out. 2017(b).

BRASIL. Instituo Brasileiro do Meio Ambiente e dos Recursos Naturais Renováveis: Coordenação de Licenciamento Ambiental de Exploração de Petróleo e gás. Parecer técnico $\mathbf{n}^{\mathbf{o}}$ 176/2018-COEXP/CGMAC/DILIC. Dispõe sobre Análise da resposta ao PT 106/17-EIA ATIV PERF DA BP NO BLOCO FZA-M-59. 2018. Disponível em: <http://licenciamento.ibama.gov.br/Petroleo/Perfuracao/Perfuracao $\% 20-\% 20 \mathrm{Bacia} \% 20 \mathrm{da} \% 20 \mathrm{Foz} \% 20 \mathrm{do}$ $\% 20$ Amazonas $\% 20-\% 20$ Bloco $\% 20 F Z A-M-59 \% 20-\% 20 B P /$ Pareceres $\% 20$ Tecnicos $\% 20$ do \%20IBAMA/PT\%20176-18\%20-\%20Analise \%20EIA $\% 20$ Rev $\% 2001 \% 20$ FZA $\% 20 B P \% 20$ (SEI\%203282273).pdf > Acessado em: 06 fev. 2019.

FARIA, G. F.; SILVA, F.M. Participação pública no processo de avaliação de impacto ambiental no Estado do Espírito Santo.2017. Desenvolvimento e meio ambiente. Vitória - ES, v. 43, Edição Especial: Avaliação de Impacto Ambiental, dez. 2017.

GLUCKER, A. N.; DRIESSEN, P. P. J.; KOLHOFF, A.; RUNHAAR, H. A. C. Public participation in environmental impact assessment: why, who and how? Environmental Impact Assessment Review, 43, 104-111, 2013.

GOULART, M. B. Participação social no licenciamento ambiental das atividades de E\&P de petróleo na Bacia de Campos (RJ).. Dissertação de Mestrado. Universidade Federal Fluminense, Niterói. 2009. 156p.

GOULART, M. B.; AMARAL, S. P. Participação social no licenciamento ambiental das 
atividades de E\&P de petróleo na Bacia de Campos (RJ). in: Congresso Nacional de Excelência em Gestão: Gestão do Conhecimento para a Sustentabilidade, 5., 2009, NiteróiRJ. Anais.... Niterói-RJ: ISSN 1984-9354. 2009. Disponível em: <http://www.inovarse.org/ filebrowser/download/10061>Acessado em: 06 fev. 2019.

MARTINI, K. M.; SOUZA-LIMA, J. E. Audiência pública: garantia ou negação de cidadania ambiental. Revista Meio Ambiente e Sustentabilidade. Vol. 9, n. 4. Jul.-Dez, 2015.

NEGEV, M.; DAVIDOVITCH, N.; GARB, Y.; TAL, A. Stakeholder participation in health impact assessment: a multicultural approach. Environmental Impact Assessment Review, 43, 112-120, 2013.

SÁNCHEZ, L. H. Avaliação de impacto ambiental: conceitos e métodos. 2. ed. São Paulo: Oficina de Textos, 2013.

SILVA, A.C.A.; SILVA, L.P.S. Participação popular no licenciamento ambiental: as audiências públicas do aproveitamento hidrelétrico (AHE) Ferreira Gomes - AP. Monografia (Bacharel em Ciências Ambientais) - Universidade federal do Amapá, Macapá-AP, 2014. 